Neurosurg Focus 8 (4):Clinical Pearl 1, 2000, Click here to return to Table of Contents

\title{
Contralateral subdural hematoma resulting from intraoperative aneurysm rupture
}

\section{Case illustration}

\author{
Gabriel Gonzales-Portillo, M.D., and Roberto C. Heros, M.D. \\ Department of Neurological Surgery, University of Miami School of Medicine, Miami, Florida
}

KEY WORDS: - SUBDURAL HEMATOMA • INTRAOPERATIVE ANEURYSM RUPTURE

A 42-year-old woman suffered a subarachnoid hemorrhage. Angiography revealed a downward-pointing anterior communicating artery (ACoA) aneurysm, which we believed was the cause of the hemorrhage, as well as an ipsilateral ophthalmic artery aneurysm (Fig. 1). We operated immediately without using lumbar drainage. As we opened the dura, the aneurysm ruptured massively. Within seconds, the patients brain started to protrude through the operative site. We were required to use suction continuously on our pathway to the aneurysm through the frontal lobe. The aneurysm was satisfactorily clipped within a couple of minutes; however the brain continued to protrude alarmingly through the craniotomy site. Ultrasound exploration did not reveal an intracerebral or intraventricular hematoma, and thus we closed the incision rapidly and obtained a computerized tomography (CT) scan. The CT scan revealed a large contralateral subdural hematoma (Fig. 2), which subsequently was successfully evacuated.

The development of subdural hematomas as a result of aneurysm rupture has been well described. ${ }^{1-4}$ Bilateral subdural hematomas have been caused by the rupture of an ACoA. ${ }^{4}$ Our case is unique because the contralateral subdural hematoma occurred as a result of an intraoperative rupture. There is no doubt of this causal connection because the massive herniation of the brain coincided, within seconds, with the rupture of the aneurysm. At this

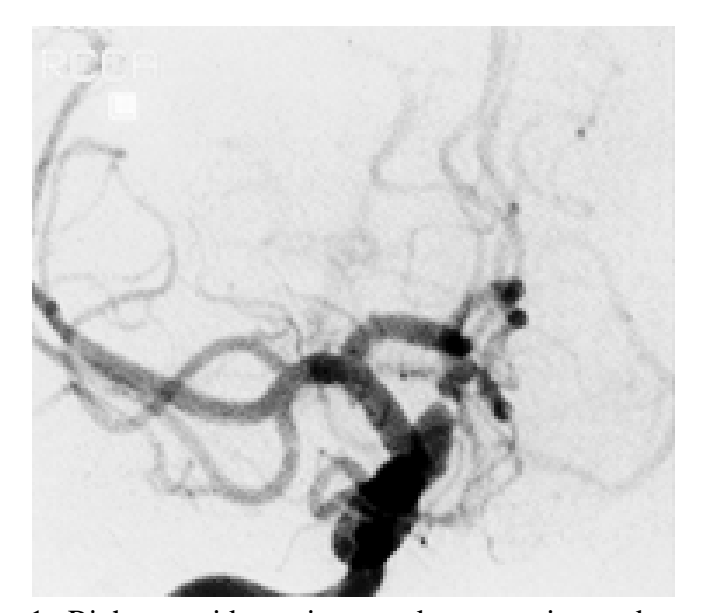

Fig. 1. Right carotid arteriogram demonstrating a downward pointing ACoA aneurysm and an incidental paraclinoid aneurysm. time we were able to suction the blood that emerged through the operative site, but not the blood that was accumulating in the contralateral subdural space. We hope this paper will alert neurosurgeons of this possibility.

\section{References}

1. Barton E, Tudor J: Subdural haematoma in association with bleeding intracranial aneurysm. Neuroradiology 23:157-160, 1982

2. Bassett RC, Lemmen LJ: Subdural hematoma associated with bleeding intracranial aneurysm. J Neurosurg 9:443-450, 1952

3. Boop WC Jr, Chou SN, French LA: Ruptured intracranial aneurysm complicated by subdural hematoma. J Neurosurg 18:834-836, 1961

4. Handel SF, Perpetuo FOL, Handel CH: Subdural hematomas due to ruptured cerebral aneurysms: angiographic diagnosis and potential pitfalls on CT. AJR 130:507-509, 1978

Manuscript received September 8, 1999.

Accepted in final form March 6, 2000.

This article appears with the permission of the Journal of Neurosurgery and can be seen in the July 2000 issue.

Address reprint requests to: Roberto C. Heros, M.D., Department of Neurological Surgery, University of Miami School of Medicine, 1501 NW 9th Avenue, Miami, Florida. email: rheros@med. miami.edu.

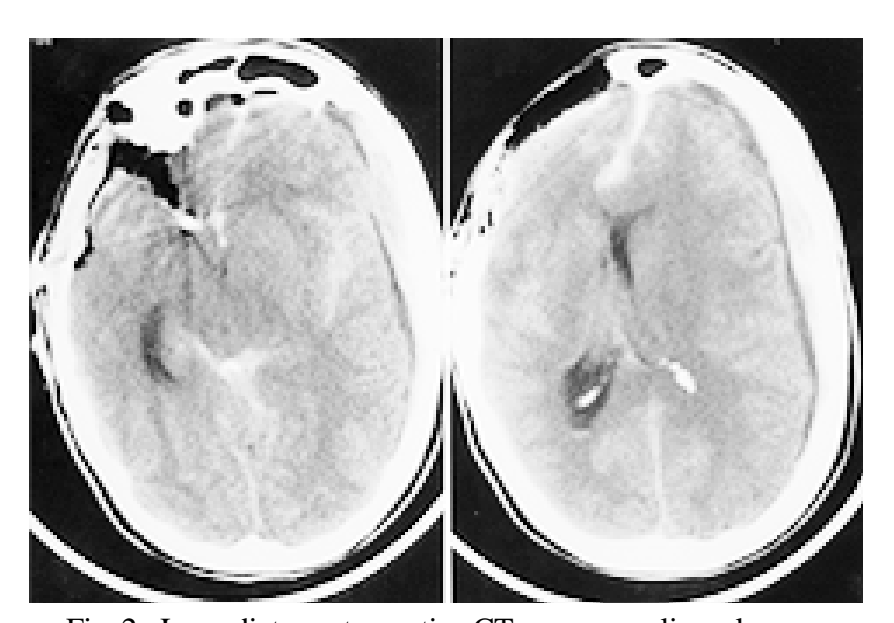

Fig. 2. Immediate postoperative CT scans revealing a large contralateral subdural hematoma and the track in the brain through which surgeons proceeded to clip the aneurysm. 